Article

\title{
Positioning the Urban in the Global Knowledge Economy: Increasing Competitiveness or Inequality
}

\author{
Tatjana Boczy ${ }^{1}$, Ruggero Cefalo ${ }^{1}$, Andrea Parma ${ }^{2, *}$ and Rikke Skovgaard Nielsen ${ }^{3}$ \\ ${ }^{1}$ Department of Sociology, University of Vienna, 1010 Vienna, Austria; E-Mails: tatjana.boczy@univie.ac.at (T.B.), \\ ruggero.cefalo@univie.ac.it (R.C.) \\ 2 Department of Architecture and Urban Studies, Polytechnic of Milan, 20133 Milan, Italy; E-Mail: andrea.parma@polimi.it \\ ${ }^{3}$ Department of the Built Environment, Aalborg University, 9220 Aalborg, Denmark; E-Mail: rsn@sbi.aau.dk \\ * Corresponding author
}

Submitted: 15 June 2020 | Accepted: 7 September 2020 | Published: 3 December 2020

\begin{abstract}
Major cities are increasingly focused on being competitive on an international scale, developing innovative service sectors and investing in human capital. This has contributed to reshaping local socio-economic systems towards a knowledge economy by strategically fostering key business clusters. But what happens in terms of social inequality in this process? The purpose of this article is to analyse whether issues regarding challenges of social inequality and polarisation are considered in the strategies of urban centres positioning themselves in the global knowledge economy. This leads to a discussion about how the cities' strategies address potentially growing inequalities, combining goals of competitiveness, internationalisation and social inclusion. The article builds on case studies from Milan in Italy, Vienna in Austria and Aarhus in Denmark. The three cities are all drivers of growth in their respective regions and countries and are embedded in different national welfare regimes. At the same time, they display internal spatial differentiation in that the municipality covers areas of growth and affluence as well as deprivation. In the article, we combine analysis of policy documents and interviews with governance, business and community actors from the three locations. Our results show that the association between competitiveness and integration is shaped through specific state-city relationships, highlighting both the importance of the welfare framework and the specific urban policy tradition.
\end{abstract}

\section{Keywords}

Austria, Denmark, inequality; internationalisation; Italy; knowledge economy; high skills; social cohesion; social inclusion; urban context; urban policy

\section{Issue}

This article is part of the issue "Cohesion in the Local Context: Reconciling the Territorial, Economic and Social Dimensions," edited by Anja Jørgensen (Aalborg University, Denmark), Mia Arp Fallov (Aalborg University, Denmark), Rikke Skovgaard Nielsen (Aalborg University, Denmark), Hans Thor Andersen (Aalborg University, Denmark) and Maja de Neergaard (Aalborg University, Denmark).

(C) 2020 by the authors; licensee Cogitatio (Lisbon, Portugal). This article is licensed under a Creative Commons Attribution 4.0 International License (CC BY).

\section{Introduction}

Major European cities are increasingly focused on staying competitive on an international scale by becoming service hubs and investing in human capital. Starting in the 70s, after the oil shock, the Fordist economic structure began its decline. In Western Europe, the weight of the industrial sector (especially manufacturing) fell inexorably. While the main large-scale industries were relocated to countries where the workforce was less expensive, led by the United States, the service economy increasingly became the main source of employment in Western countries (Rowthorn \& Ramaswamy, 1997). Simultaneously, educational attainment increased and education levels have become strongly linked to the probabilities of employment in the EU countries (Landesmann \& Römisch, 2006). 
Within this framework, the knowledge economy has gained particular traction (OECD, 1996) and knowledge has become the main asset in wealth creation (DTI, 1998). The knowledge economy not only involves the service sector but also the productive sector, accentuating new production structures that exploit technological advances. This movement towards the service sector and the expanded focus on knowledge economy implies a change in the required skills of the workforce. Individuals who cannot keep up with the new labour market requirements risk social exclusion. However, while the knowledge economy becomes a new source of wealth, it also emphasises differences between territories (Castells, 1996). These differences relate not only to inequality between countries and regions but also to gaps within cities between affluent and deprived areas.

Indeed, economic growth strategies can increase the average level of well-being but, at the same time, they may overlook internal inequalities of cities or even contribute to their increase. This risk is particularly evident for growth strategies based on policies aimed at promoting service centres and knowledge economy hubs. According to Cucca and Ranci (2016), such economic competitiveness policies can impact inequality in two ways. First, the expansion of the knowledge economy is usually matched by a rise in low-qualified jobs needed to support those services. Second, such strategies tend to disproportionately benefit some groups: New wellqualified and well-paid jobs are created but they attract outside people with certain skills and qualifications, such as the creative class and the new urban middle class described by Florida (2002), while leaving a struggling stratum of the local population behind.

In European cities, urban policies that pursue economic competitiveness have generally been successful in attracting foreign investment and new populations to cities (Musterd \& Murie, 2010). However, at the same time, they have fostered a rising disconnection between economic growth and social integration. This can lead to both social and spatial polarisation (Cucca \& Ranci, 2016).

The rising disconnection between economic growth and social integration is a crucial issue to be investigated in different European urban contexts, to understand if the challenges of growing inequalities are recognised and tackled. The traits and potential drawbacks of the globalised and technology-intensive economy have been widely discussed in the literature (Kenway, Bullen, Fahey, \& Robb, 2006; Lundvall, 2016), looking in particular at the national and supranational scale. Less attention has been directed to how cities deal with the polarising effects of the knowledge economy, although the increase of social vulnerabilities and inequalities in European cities has been recognised as a crucial topic for urban and social policy analysis (Ranci, Brandsen, \& Sabatinelli, 2014).

In order to promote local growth, urban centres are increasingly seeking to position themselves in the global knowledge economy. The risk is that the distri- bution of wealth produced by successful growth strategies would disproportionally benefit some sections (intended both as socio-economic groups and geographical portions) within the cities, leading to an increase of the internal inequalities. Policies that can tackle inequalities, such as education and welfare policies, are often designed at the national or regional level rather than the city level. However, the mix of local autonomy, rescaling processes and local social innovation can contribute to combine the development of the knowledge economy with the reduction of inequalities at the city level. Moreover, the unequal spatial distribution of vulnerabilities and the concentration of social problems in big cities suggest that 'locality' profoundly matters in the configuration of the disconnection between economic growth and social integration.

Given these premises, by comparing three European cities (Aarhus, Milan and Vienna) embedded in different welfare regimes, this article aims to analyse if and how local growth strategies address the challenges regarding social inequality. By doing this, we provide novel comparative evidence on the relationship between economic growth and social cohesion, looking at it from the perspective of urban growth strategies. The analysis of main strategy documents is supplemented with interviews of local actors to consider how these issues are shaped in the local debate. The objective is not to analyse the outcomes of the implemented actions, but instead to focus on whether and how local policymakers are considering the potential social criticalities of the growth strategies promoted now that knowledge-based economy strategies are well-established along with their consequences.

\section{The Rise of Knowledge and Learning Economy}

In post-industrial societies, the massive shift towards internationalisation and tertiarisation of the economy was matched with unprecedented technological advancement, especially in sectors like engineering, information and communication (Esping-Andersen, 1999). Knowledge, skills and innovation are the critical resources for competitive advantage. Accordingly, the knowledge economy has been defined as "production and services based on knowledge-intensive activities that contribute to an accelerated pace of technical and scientific advance, as well as rapid obsolescence" (Powell \& Snellman, 2004). Enterprises basing their organisation on the principles of lean production or discretionary learning show higher productivity gains and benefit the most from the opportunities created by the knowledge economy (Arundel, Lorenz, Lundvall, \& Valeyre, 2007). Conversely, traditional and Taylorist organisations are more vulnerable to the cycles of international competition. Jobs that entail intensive use of technology and competencies represent the main drivers of economic growth. This is documented by a relative shift in the demand for labour, as employers demand highly qualified and high-skilled workers. Hence, education, training and 
skills represent the backbone of this economy on the side of labour-supply. As stated by Lundvall (2016), the success of individuals, firms, regions and countries reflect their ability to learn.

The rise of the knowledge economy entails a high demand for specialised and highly skilled labour, producing spill-over effects for the creation of jobs in related sectors and fostering demand for the 'upskilling' of workers (ESPON, 2017). Large metropolitan areas and their suburbs become centres of agglomeration, specialisation and cumulative advantage that show strong dynamism in terms of income and employment creation (Dijkstra, 2017). Technological developments and regional innovation lead to a growing demand for higher-skilled workers and consequent labour-pooling from other regions and countries.

Research has emphasised the negative impact and the risks associated with the rise of the knowledge economy. Several scholars have analysed the outcomes of uneven economic development in contemporary postindustrial societies by addressing the rise of precarisation and dualisation (Emmenegger, Häusermann, Palier, \& Seeleib-Kaiser, 2012), the forms of skill-mismatch between supply and demand of competencies (Autor, 2014) and the socially dividing role of education in the context of market-driven, globalised competition (Brown, Lauder, \& Ashton, 2010).

Cities, hit by the closure of traditional factories, invest in sectors based on immaterial values. Development strategies are based on the 'creative city' model (investments in technology-intensive manufacturing, services, cultural industries and neo-artisanal design) in order to promote cities in the new global arena (D'Ovidio, 2016). However, in pursuing such strategies they tend to focus on amenities and the built environment (Vicari, 2010) to attract the new professionals overlooking the historical roots of different places and the social consequences of these strategies.

From a spatial perspective, the dark side of knowledge diffusion and concentration is the generation of territorial polarisation and inequalities (lammarino, Rodriguez-Pose, \& Storper, 2018). The presence of a competitive knowledge economy increases the flow of human and social capital, developing spatial concentration of firms and high population density with high education levels. However, less competitive regions are challenged by brain-drain dynamics of highly skilled people migrating, often becoming dependent on the returning inflow of remittances and knowledge workers (ESPON, 2017).

Besides polarisation between countries and regions, widening gaps between affluent and deprived areas within larger cities arise as a consequence of sharp increases in inequalities and poverty, leading to the intensification of social tensions and vulnerabilities (Glaser, Resseger, \& Tobio, 2008). Cities that are increasingly integrated into the global flows of the knowledge economy must cope with significant internal inequalities and social polarisation to the point that "disparities within a given city have largely surpassed disparities between cities" (OECD, 2006, p. 145). During the Fordist period, competition and integration maintained a certain balance, as the search for equity and spatial integration was accompanied by significant economic performances (Bagnasco \& Le Galès, 2000). However, the expansion of the knowledge economy, which made these cities more competitive internationally, also contributed to the spread of social tensions within the urban context.

Looking at the dynamics of work-demand, the expansion of the knowledge-intensive service sector with highly productive jobs required the functional support of a parallel growth of low-qualified services (e.g., care work, cashiers, cleaners, etc.). These scarcely productive jobs (Esping-Andersen, 1999) are associated with lower salaries and a high risk of precarity and social exclusion. Concerning the supply of work, a consequence of the skill-based technological change (Berman, Bound, \& Machin, 1998) is that many job seekers may lack the qualifications and skills requested by employers. Low-skilled individuals, often with disadvantaged socio-economic or migration background, are faced with the perspective of alternating periods of unemployment and employment in low-qualified service jobs. For these groups, the situation leads to worsening life chances and higher risks of social exclusion (Rodrigues, 2006). The divide between those who benefit from economic development and those who are left behind is often expressed by patterns of spatial segregation. Economic and skill-intensive growth attracts a highly educated and affluent labour force that tends to live in the more attractive areas of the city in stark contrast to deprived areas, where vulnerable groups concentrate.

The unequal spatial distribution of vulnerabilities and the concentration of social problems in big cities suggest that 'locality' profoundly matters in the configuration of the disconnection between economic growth and social integration. Nonetheless, cities are embedded in welfare architectures at the national level. The role of cities in the provision of social policies and services to protect vulnerable groups of the population must therefore be read in the wider context of national welfare states pertaining to different regimes or worlds of welfare (Esping-Andersen, 1990). This state-city dynamic is essential for understanding the capacity of the city to limit the spread of polarisation and inequalities associated with economic development, indicated as a crucial characteristic of the European city model (Häußermann \& Haila, 2005). However, this capacity appears now to be fragmented, due to the new challenges associated with the rise of the knowledge economy, as well as with dynamics of expenditure cuts and welfare reorganisation increasing the role of local welfare provision in multilevel governance structures (Kazepov, 2010). As a result of the crisis of the European city model (Häußermann, \& Haila, 2005), a growing disconnection between economic growth and social integration is observed (Cucca \& Ranci, 2016). Its developments and variations across 
European cities represent a crucial topic for urban and social policy analysis. Thus, given the ambiguous impact of the knowledge economy in urban contexts, this study delves deeper into the issue by comparing three European cities, to investigate if inequalities are considered in urban growth strategies.

\section{Methods}

The article builds on three city cases: Vienna, Milan and Aarhus. Key figures for the three cities are presented in Table 1. Vienna is the capital of Austria and both a municipality and a federal state. It has 1.8 million inhabitants and is the economic and social centre of the country. Milan is a leading Italian industrial city and the main economic and financial centre of Northern Italy. It has 1.4 million inhabitants. Aarhus is by international standards a medium-sized city of approximately 350,000 inhabitants. Nevertheless, it is the second biggest city of Denmark and the growth driver of its region and Jutland more generally. The three cases have been chosen for being economic centres of their respective regions and for being major university cities. The first point makes them key growth drivers of their respective regions, which in turn makes growth policies central for each municipality. The latter point means that they are knowledge centres, not only attracting young people to study but also attracting businesses looking to benefit from the highly skilled workforce. All three cases are characterised by population growth, by being a centre for migration and for having more in-commuters than out-commuters. This all sig- nifies to the cities being national and regional growth centres. At the same time, they all contain internal spatial differentiation in that the municipality covers areas of growth and affluence as well as deprivation. As the three cities share similar key parameters, it is reasonable that comparing them will shed further light on the implications of economic growth strategies for social inequality in different contexts. The differences between the case characteristics indicate that the conclusions are likely to be of wider relevance than if the cases had been very similar (Flyvbjerg, 2006).

Most of the empirical basis for the case studies is key documents from each of the three cases, mainly strategy papers, policies and overall strategies related to growth and internationalisation (Table 2). Initially, a policy archive was constructed of documents from each case. All relevant policies since 2012 were gathered within five policy fields: economic growth, active labour market, vocational educational training, childcare and urban regeneration. The latest policy (e.g., the latest business plan) and its predecessor were included. All policies in the archive were mapped, describing, e.g., key characteristics and main points. On this basis, the policies that describe the current local economic, growth and internationalisation strategy were identified and analysed. Qualitative content analysis was conducted based on a thematic coding (Guest, MacQueen, \& Namey, 2012). Such an analysis entails identifying themes in the text, coding them and establishing patterns between the themes. Coding was mainly deductive and the themes in the focus of the coding and subse-

Table 1. Comparative data about the cities considered.

\begin{tabular}{|c|c|c|c|c|c|c|}
\hline Indicator & Aarhus & Denmark & Vienna & Austria & Milan & Italy \\
\hline $\begin{array}{l}\text { Population, } \\
\text { January } 2019\end{array}$ & 345,208 & $5,806,081$ & $1,897,491$ & $8,858,775$ & $1,378,689$ & $60,359,546$ \\
\hline Area (km2) & 468 & 42,933 & 414.9 & 83,879 & 181.67 & 302,073 \\
\hline $\begin{array}{l}\text { Population density, } \\
\text { January } 2019\end{array}$ & 738 & 135 & 4,573 & 106 & 7,589 & 200 \\
\hline $\begin{array}{l}\text { 5-year population } \\
\text { change }(\%, 2014-2019)\end{array}$ & $+6.6 \%$ & $+3.2 \%$ & $+7.4 \%$ & $+4.16 \%$ & $+1.04 \%$ & $-0.7 \%$ \\
\hline $\begin{array}{l}\text { Tertiary education } \\
\text { (aged 25-64) }\end{array}$ & $55.1 \%$ & $40 \%$ (2018) & $32.7 \%$ (2019) & $33.8 \%$ (2019) & $33.3 \%$ (2011) & $15.0 \%(2011)$ \\
\hline $\begin{array}{l}\text { Total unemployment } \\
\text { rate (\%) }\end{array}$ & $5.3 \%(2018)$ & $5.0 \%(2018)$ & $10.4 \%$ (2017) & $4.5 \%$ (2019) & $6.9 \%(2017)$ & $10.0 \%(2019)$ \\
\hline $\begin{array}{l}\text { Share of managers, } \\
\text { professionals* }\end{array}$ & $36.5 \%$ (2018) & $28.0 \%$ (2018) & $24.0 \%$ (2011) & $16.6 \%(2011)$ & $31.7 \%$ (2011) & $18.9 \%(2019)$ \\
\hline GINI & 32.9 (2018) & 29.1 (2018) & 33.7 (2013) & 26.8 (2018) & 53.5 (2017) & 43.1 (2017) \\
\hline
\end{tabular}

Note: * Managers and professionals are defined as major groups 1 and 2 of ISCO-08. Aarhus and Danish figures estimated not including self-employed. Sources: Aarhus Kommune (n.d.) and Statistics Denmark (n.d.) for Denmark, last accessed 20 August 2020; Vienna Municipality Statistical Office (n.d., last accessed 12 August 2020), Statistics Austria (n.d., last accessed 24 August 2020), Eurostat (n.d., last accessed 12 August 2020) and OECD Statistics (n.d., last accessed 24 August 2020) for Austria; ISTAT (n.d., last accessed 20 August 2020), Eurostat (n.d., last accessed 12 August 2020), Camera di Commercio di Milano, Monza Brianza e Lodi (2020) for Italy. 
Table 2. Documents considered.

\begin{tabular}{|c|c|}
\hline Document & Year \\
\hline \multicolumn{2}{|c|}{ Vienna } \\
\hline Urban Development and Planning 2025 & 2014 \\
\hline Innovative Vienna 2020 & 2015 \\
\hline Qualification Plan Vienna 2030 & 2018 \\
\hline Productive City & 2017 \\
\hline Smart City Vienna: Framework Strategy & 2014 \\
\hline Smart City Vienna 2019-2050 & 2019 \\
\hline
\end{tabular}

Aarhus

Planning Strategy 2015

$\begin{array}{ll}\text { Municipal Plan } 2017 & 2017\end{array}$

International Strategy for Growth in Aarhus 2017

Business Plan 2018-2019, Overview 2017

Milan

Documento Unico di Programmazione, Milan Municipality 2017

Programmatic lines related to projects and actions to be carried out during the mandate, Milan Municipality 2016

Manifattura Milano 2017

Milano Smart City, Guidelines 2014

Call for the peripheries 2018, Guidelines 2018

Master Plan (Piano del Governo del Territorio) 2019

quent analyses were economic growth, knowledge economy, internationalisation, inequality, spatial differentiation and polarisation.

The documents are supplemented with interviews with governance, business and community actors. These interviews were included to shed further light on the ideas behind and the consequences of the strategies and policies, focusing on the interviewees' perception of the background for the policies and their implication for economic growth, knowledge economy, internationalisation, inequality, spatial differentiation and polarisation. Interviewees were chosen to represent key actors in the policy fields; both governance actors involved in formulating and implementing the policies as well as business and community actors affected by the policies.

For the larger project, of which this work is part, 20 interviews for each case were conducted. In relation to the current theme, the relevance of these interviews varied, which means that, in the analysis for this article, 17 interviews supplement the written material: five for Vienna, six for Aarhus and six for Milan (Table 3). For a further description of the methodological approach, see de Neergaard, Arp Fallov, Skovgaard Nielsen, and Jørgensen (2020).

\section{Analysis}

In this section, we outline the main growth strategies pursued in the three cities, focusing on whether and how they address issues related to social inclusion and inequalities.

\subsection{Vienna}

In Vienna, documents and interviews describe the city as the business, educational, research and cultural hub of Austria. Vienna is depicted as the focal point of exciting international developments that opens economic opportunities (Vienna Municipal Department 18, 2014a, p. 9), due to it being the capital city and the geographic location as a "doorway to the East" of Europe. This collective identity is reflected in documents as well as interviews with public and business actors. Both data sources also agree on the importance of developing a dynamic knowledge economy in the city.

\subsubsection{Focus on Knowledge Economy Development}

In 2007, the city government launches its first RTI strategy focusing on "human resources, thematic focuses [i.e., life sciences/medicine, ICTs and creative industries/media], awareness, enabling developments [and] Vienna as an international hub" (Vienna Municipal Department 23, 2015, p. 11). Even though the knowledge sectors ICT, service, research and pharma industry play an increasingly central role in Vienna's economic development, the city strives for an economic mix by creating land reserves for (returning) classical industry production sites (Vienna Municipal Department 18, 2014b).

The city government lays out several strategies to remain competitive in the global knowledge economy. A comprehensive 10-year development plan is accompanied by specific strategies like Innovative Vienna 
Table 3. Profile of interviewees quoted.

Interviewees organisation

Vienna

Chamber of Commerce, Division Economic Policies, Labour Market and Statistics

Public Employment Services Vienna

Business District Management Vienna

ATB15

Production Company in Vienna

ATB2

Public Company, Division Education Centre and Vocational Training

Aarhus

Business Region Aarhus

Business Promotion Aarhus

Aarhus Municipality, Citizenship

DKP11

Aarhus Municipality, Employment

DKP12

Agro Food Park (Business cluster)

DKB2

Developer

DKB3

Milan

Municipality of Milan (City Councillor)

Third Sector Organisation (Chairman)

Member of administration councils of various companies

Municipality of Milan (Civil servant)

Business Association (Director at Lombardy branch)

Municipality of Milan (Civil servant)

(2015), Qualification Plan Vienna (2018), Productive City (2017) or Smart City Vienna (2014, 2019). Even though these documents address different aspects, they all outline strategies and measures for an urban knowledge economy. The comprehensive Urban Development Plan 2025 defines knowledge economy as economic activities based on knowledge that sparks the development of new knowledge and innovative high-tech products "composed of three interlinked pillars - universities, high-tech production and knowledge-intensive services" (Vienna Municipal Department 18, 2014a, p. 138

Overall, the strategies outline the development of the knowledge economy as related to population growth and the fight against the re-location of industries outside the city. Consequently, the city government wants to invest in quality education and "ensure skill-building for residents to enable them to meet the employment requirements emerging in the region" (Vienna Municipal Department 18, 2014a, p. 69). Specifically, low-educated youths and adults are the target groups for supporting measures to gain higher than compulsory education (Vienna Municipal Department 23, 2018). To this end, the educational strategy (Vienna Municipal Department 23,2018 ) strives to foster collaboration and coordination between social partners, companies and public administration. It also advertises its educational programmes to the target audiences and companies to spark a Life-LongLearning mind-set (Vienna Municipal Department 23, 2018, p. 46; ATB2). Additionally, strategic land-use and expansion of the public transportation system are seen as vital factors in sparking innovation, creativity and sustainable economic development.

Vienna's strategic documents jump over the national scale by rarely addressing national policies or strategies (Kazepov, Saruis, \& Colombo, 2020). Instead, the city's strategies look towards supranational (EU) and international institutions to guide its policy set-up. This institutional scale jumping of legitimation for measures and funding highlights the city's international perspective. This indicates an understanding of embeddedness within the international and, especially, European context. Moreover, a culture of collaboration is fostered with neighbouring areas and countries, for instance with the city of Budapest, as a potential "economic hub, workplace and place of living" (Vienna Municipal Department 18, 2014a, p. 93).

\subsubsection{Inclusion and Equity in the Knowledge Economy}

In the strategies, descriptions of social inclusion concern ethnic minorities, low-income groups, women, ethnical groups, poor and elderly, unemployed (especially those with low skills or formal education attainment and mature workers) and NEETs (Vienna Municipal Department 18, 2014). Documents refer to social work outsourced to associations and the role of NGOs, which are vital in battling social and democratic exclusion. The documents address gender inequality and difficult access to the labour market for people with low education. Social inclusion is quite often mentioned concern- 
ing infrastructure and equal access, e.g., to education and health facilities. The documents present the funding of education and re-training as crucial tools to help NEETs and mature workers (50+ years) back into the labour market and to tackle poverty and low income (Vienna Municipal Department 18, 2017). Access and quality of ECEC and (compulsory) education are identified as central to social mobility.

Education is described as essential in documents and interviews across actor types. However, interviewees mention a lack of resources for tertiary education. One business actor interviewee described this lack of funding as costing the city international reputation, especially within rankings of universities (ATB2). Moreover, interviewees mentioned the struggle to recruit qualified workers and the challenge of higher education including incompany vocational training (ATB2, ATP3, ATP5, ATP13, ATB15). These responses indicate a mismatch between education and labour market demands.

The demand for higher academic qualifications and the recruitment of international labour also means, for those with low formal education, a high risk of unemployment and marginalisation in less affluent areas within the city. Vienna struggles with a higher unemployment rate than other areas in Austria. Similarly, documents mention technological changes and how they affect labour market conditions for low-skilled workers (Vienna Municipal Department 23, 2015). In terms of measures and policies adopted, these concerns are reflected in a wide array of targeted youth and adult training. The city government, social partners and EU funds invest in training programmes to address the consequences of automatisation and global competition and establish a local knowledge economy.

Overall, though, the documents barely address inequality in spatial forms, instead focusing on groups identified as most at risk of exclusion. Thereby, issues of territorial inequality are not considered within as well as beyond the city limits. Instead, challenges accompanied by becoming a knowledge economy are treated as nonstructural ills of specific groups and individuals. These ills are presented as treatable through re-training and skill development. Additional pitfalls like the precarisation of knowledge workers, the dualisation of society or skill-mismatch are not addressed. In this way, Vienna seems to start initiatives to become a competitive knowledge economy but insufficiently addresses structural social tensions or negative consequences of its knowledge economy strategies.

\subsection{Aarhus}

Aarhus is a city of growth in many ways: in population, employment and number of workplaces, but particularly in knowledge and service industries. It is the main growth motor of the novel 12-municipality collaboration Business Region Aarhus (BRAA). Correspondingly, a focus on growth permeates the strategic documents of Aarhus.
The overall Planning Strategy 2015: Clever Growth towards 2050 (the main aims of which are continued in the Planning Strategy 2019, passed in early 2020) and the Municipal Plan 2017 describe clever growth as developing the city sustainably, socially, economically and environmentally, while creating better city qualities and a higher level of liveability (Aarhus Municipality, 2015, 2017a). Growth is expected to come from education and talent recruitment: "Aarhus shall be a leading knowledge, education and culture city, and the Aarhus region shall be one of Northern Europe's most attractive job and career destinations" (Aarhus Municipality, 2018, p. 4).

\subsubsection{Focus on Knowledge Economy Development}

Since the late 1990s, Aarhus Municipality has been supporting the built-up of clusters based on international examples; being pioneers in a Danish context (DKP5). Currently, main efforts are focused on clusters on foodstuffs, health and energy, climate and ecology. The municipality supports them through the branding of the region to attract labour, investments and tourism as well as through favourable legal framework for entrepreneurship and business development, effective regulatory processing and political and administrational support for businesses as well as clear strategic plans (DKB2, DKB3, DKP6).

Aarhus is described as "a small big city" (DKP11). Tales of the advantages of being smaller than the country's capital permeate the interviews, e.g., pointing to the advantage of strategic actors knowing each other, which facilitates dialogue, coordination and decisionmaking (DKP6). At the same time, much emphasis is put on being the biggest city in the region, the region's growth motor and the key actor in BRAA (e.g., DKP12 and Business Plan 2017). The city's population growth comes from all the people moving to the city to study (DKP12, DKP6). Consequently, businesses and organisations have a highly-skilled workforce to pick from which makes the city an attractive home to a range of major companies. Education and the attraction of international talent and labour are returning elements in the strategic documents on economic growth, describing Aarhus as consolidating its position in the knowledge-based global value chain with education as a cornerstone (Aarhus Municipality, 2015). At the same time, the broad economic profile of Aarhus is referred to as an advantage that should be sustained, e.g., through continuing to have industry-heavy businesses in the city in suitable places. The broad profile is seen as future-proofing the city, making it less dependent on specific industries.

The overall vision of Business Plan 2018-2019 is for Aarhus to develop into "a national growth-centre with international impact" (Aarhus Municipality, 2017c, p. 4); thus, positioning Aarhus in relation to both a national and an international scene. The International Strategy for Growth in Aarhus contains recommendations for strengthening the municipality's internationalisation through attracting international talent, businesses 
and investment (Aarhus Municipality, 2017b). The strategy underscores the municipality's international ambitions with the returning emphasis on "international competition" and "fight for growth" and the role of diversity and community in this interplay: "We want to internationalise Aarhus further in the coming years in order to strengthen the city's openness, diversity and its understanding of the necessity of internationalism (Aarhus Municipality, 2017b, p. 4). Potential downsides of globalisation are not addressed. Globalisation is portrayed as a train on the move that one cannot afford to be late for. One part of this is recruiting and retaining international labour and talent in competition with other cities. The municipality uses its position in both Northern and European regional urban networks to promote its position internationally.

\subsubsection{Inclusion and Equity in the Knowledge Economy}

Being an inclusive city with 'room for all' is a central narrative in strategic documents from Aarhus. However, like the potential downsides of globalisation, neither inequality nor equal opportunities are addressed in the strategic documents on growth and internationalisation. The foreword to the internationalisation strategy states that increased globalisation and internationalisation requires municipalities to take advantage of the possibilities of globalisation (one of them being growth) while mitigating the worst challenges of globalisation. It is the only place where challenges are mentioned directly, and there is no specification of what these challenges entail.

Growth strategies are seen as the motor for the development of the region and the city but also for the development of the deprived urban areas more specifically. There is a focus on mediating the consequences of uneven growth, both territorially and socially, and an aim to distribute growth spatially to all areas of the city (even while describing specific growth areas and growth axis). Growth is described as beneficial for everyone if planned for in the right way. In making room for all, two main focuses are mentioned: to secure more room for the middle-classes in Aarhus and to ensure that the deprived areas also benefit from growth through a holistic effort to change their situation. The most direct reference to inequality is to the existence of deprived areas that have to take part in the growth to make them no longer stand out from the rest of Aarhus (Aarhus Municipality, 2015). Growth is described as being able to create a greater municipal investment for distribution, leading to new offers and service solutions for the most deprived (DKP6).

Overall, the narrative in Aarhus centres on economic growth as a motor for development for the whole city, including the deprived areas. Growth is to benefit everyone in the city; however, it is not clear how this is to be achieved, i.e., how growth is to be distributed spatially and socially. Likewise, globalisation is described as a train on the move that one cannot afford to be late for. That there might be downsides to growth and globalisa- tion is largely overlooked. At best, they are hinted at, and there are no traceable efforts to mediate the social consequences of growth.

\subsection{Milan}

Milan's economic structure is that of a knowledge economy with a strong international vocation (Coppola, Daveri, Negri, \& Saini, 2018). The city is characterised by a multi-sectorial economy in which the historical manufacturing core, knowledge-intensive services, international companies and small and medium business coexist. The successful organisation of the Expo 2015 fair is seen to have contributed to framing Milan as a bridge between Italy and the world (Comune di Milano, 2017, p. 20), positioning the city as a global city, capable of intercepting knowledge and values present on larger markets, reworking them, and then re-introducing them into international circuits (Comune di Milano, 2019, p. 13). However, some local actors are concerned that the successful ability to attract new investors would increasingly lead towards a "dual-speed" city (ITP1, ITC2).

\subsubsection{Focus on Knowledge Economy Development}

Economic growth is seen as the main instrument to renovate the status of Milan as a European and global city. The local administration declared that generating work, especially for young people, must be Milan's obsession and in the coming years, the city must invest in new strategic clusters and create innovative entrepreneurship, favouring synergy with the university system, research centres, the cultural world and the Third Sector (Comune di Milano, 2016, p. 7).

"Milan grows: economic development, work, commerce, fashion and design, Smart City" (Comune di Milano, 2017, p. 5) was among the intervention lines declared by the new incoming administration in 2016. Two key actions emerged. First, to support innovative entrepreneurship, the focus is on knowledge-intensive start-ups through calls for tenders, building partnerships with entrepreneurs' organisations and the Chamber of Commerce and supporting incubators and accelerators. Special attention is given to start-ups with a social vocation proposing innovative services for peripheral neighbourhoods. Second, the manufacturing tradition has not been forgotten. Attention is on reforming it towards highly qualified and specialised craft activities with the aim of facilitating the return of manufacturing in the urban area, with a focus on innovative and sustainable manufacturing both environmentally and socially (Comune di Milano, 2017, p. 9). This led to the launch of the Manifattura Milano strategy (Direzione Economia Urbana e Lavoro, 2017), which aims not only to recover the manufacturing sector but also to promote a new organisational system to make this sector capable of surviving the new market and being a driver for the rest of the economy. 
In parallel with the economic development of the city, attention is paid to investment in human capital with the line of intervention supporting Milan as an educational city that enhances talents through school, university and research, youth policies (Comune di Milano, 2017 , p. 5). The competitiveness of the city should be based on the ability to collaborate between public and private entities and to coordinate professional training, university training, and centres of excellence in research and economic sectors with a high content of innovation (Comune di Milano, 2017, p. 9).

As the main service hub of Northern Italy, the public and private offer of tertiary and post-tertiary education is well developed. Internationalisation is also a key strategy pursued in the education system with approximately 12,200 international students.

However, the appeal of the city is not limited to the Italian context. It has an international vocation with some key clusters with a clear international outreach, e.g., creativity, fashion, design, culture and life sciences. Reinforcing this international outlook is a priority, as shown by the Smart City strategy which states that making Milan and its metropolitan area a Smart City is a political priority and a strategic objective to include Milan in the network of major European and international cities (Comune di Milano, 2014, p. 3). However, some limits in the current internationalisation levels have been detected, especially in the ability to attract headquarters of international companies to become the main directional centre of the Mediterranean and Middle East and in the level of global connection (especially with Asia markets; ITB3)

\subsubsection{Inclusion and Equity in the Knowledge Economy}

The local economic strategies are characterised by a multi-dimensional approach, considering also the social dimension. According to this narrative, economic growth has to be pursued with the related goal of social inclusion.

The use of technologies, innovation and knowledge is not simply linked to economic growth, but it is a tool to improve the supply of welfare services as Milan promotes new forms of community and territorial welfare, through the use of new instruments for the support and promotion of shared services and opportunities for socialising (Comune di Milano, 2014, p. 8). Milan is promoted as a laboratory of social inclusion and diversity where policies have to target different groups (the Smart Cities guidelines provide a quite detailed list of the most fragile groups), eliminating barriers and discriminations (Comune di Milano, 2014).

The Manifattura Milano considers enhancing social cohesion as the cornerstone to combine economic growth with innovation, inclusion, sustainability and the re-launch of the peripheries. However, what is not clear is how the two dimensions are connected through actions, apart from the fact that new job opportunities should be generated.
Nevertheless, the attention to the issue of inclusion included in the municipality's strategic programs is translated into a focus on the risk of increasing inequalities. Indeed, some parts of the city are benefitting more from the recent growth developments: "There are areas of the city that are struggling more. Parts of the city are moving at an incredible speed on par with high international levels. The most struggling parts are in the peripheries" (ITP6). The theme emerging both in the rhetoric of local politicians and in some programmatic lines is the risk of a 'two-speed city':

A city that is unable to reconcile the great development, the internationalisation and the greater attractiveness of the city with those who enjoy less of these benefits because paradoxically the positive moment Milan is currently experimenting risks to increase the resentment and the sense of abandonment of those who enjoy less by comparison and contrast. (ITP1)

A similar concern is also shared outside the political world. A leading figure in one of the main business associations recognises that the main challenges for Milan are the issues of social cohesion and sustainable development in its "triple dimension: economic, social and digital" (ITB5).

As a result, a series of initiatives with a clear territorial approach has been given privilege. In the last four years, the theme of physical, social and economic rehabilitation of the peripheries has been centre-stage in the debate. The municipality created a cross-department unit in charge of planning initiatives addressing peripheral areas. A periphery plan (Comune di Milano, 2018) has been drafted by the Municipality trying to bring together all actions devoted to such areas. Even if the effectiveness and coherence of this plan have been criticised by some actors (ITP1, ITC2), it shows the attempt to address the inequality issue. However, the plan seemed more like a grouping of initiatives carried out by individual city departments rather than a properly coordinated intervention strategy. Furthermore, the task of rebalancing the city clashed with the need of "playing in the background" (ITP4) since the city has only limited regulatory powers on many of the issues involved such as university education and the labour market.

Overall, the economic development strategies are based on the attempt to make Milan a 'smart' city, which is boosted as a global hub (at least by Italian standards) and to renew the traditional industry by considering technological transformations. However, the risk of creating inequalities is grasped by policymakers, third sector actors and the business world. This results in attempts to focus on the most marginal neighbourhoods, with mixed outcomes.

\subsection{Comparative Analysis}

In sum, we outline the main themes that emerge from the analysis of the growth strategies developed in our 
three cities and how they related to the theme of social inequalities.

Vienna has gained a highly international profile in the last decades, displaying its influence as a service and network hub that connects Eastern and Western Europe. In comparison, Aarhus has a more regional scope, extending to the BRAA. Finally, Milan emerges as a clear service hub for Northern Italy, with international outreach in some sectors.

The three cities present a leading profile on different key economic sectors: Vienna prioritises ICTs, creative industries and media; Aarhus' investments are focused on the development of business clusters; Milan puts a high emphasis on design and fashion, due to their highly international outlook. Education is considered a crucial growth factor and fuel for the development of the knowledge economy in all these city strategies. Especially in Vienna and Aarhus, the provision of high-quality education attracts young people and businesses by training an increasingly highly skilled labour force. This focus appears to be less present in Milan, even if it is a university hub. Possibly, the national context could play a role here, as the Italian economy is still characterised by a comparatively low-qualified and scarcely innovative supply of jobs.

While developing a rampant service-oriented knowledge economy, these cities also deal with their industrial and manufacturing past through a combination of relocation, persistence and promotion. In Vienna, the relocation of industries outside the cities coupled with attempts to retain factories and specialised workers in the city, also envisioning new spaces for production sites. Aarhus continues to have industry-heavy businesses located in specific parts of the city. Finally, Milan's strategies explicitly aim at reviving urban manufacturing through a focus on specialised technologically-advanced productions. The rhetoric emphasising the knowledge economy is accompanied by gradual changes in the economic and employment structure. The secondary sector still plays a relevant role in the urban contexts, also providing job positions to medium-and low-skilled labour force that cannot be easily redirected to knowledgeintensive sectors due to age and lack of specific training.

The cities differ as to whether and how inequality is addressed in growth strategies. In the cases of Milan and Aarhus, narratives often combine goals of growth and inclusion in the same documents. In Milan, the approach towards inequalities is spatial, as it implies an explicit focus on territories with a concentration of vulnerabilities. In Aarhus and Vienna, the approach to inequalities seems more related to specific categories and groups at risk, while the spatial dimension is less prominent. For instance, Vienna's strategies see education as the main tool to lever inequalities associated with economic development, providing opportunities to the population. The peculiar role of Vienna in the context of the federal Austrian system might play a role. The city itself is a federal state with a certain autonomy and long-standing tradition in the design and implementation of inclusive in- terventions in several policy fields. This is not to say that Vienna and Aarhus show no awareness of spatialised inequalities. Both cities show a spatial focus on deprived areas; however, rather than to deal with inequality directly, the aim is to improve infrastructure and access to services in the deprived areas: growth is often seen as a motor for development for the whole city, including the deprived areas that would benefit from the overall economic development.

The link between growth and inclusion appears thematised in all the cases investigated. In the documents, the three cities show an awareness of the main shortcomings of a developing post-industrial knowledge economy, i.e., the parallel growth of a low-service and often precarious sector and the de-industrialisation trends resulting in rising socio-economic inequalities. However, how polarisation is tackled can be described as ambiguous, at best. The strategies recognise the issue but address it in an unsystematic and often rhetorical way.

Local documents often lack in the programming of specific tools for intervention, as they rather tend to assume a beneficial spill-over effect of economic growth. Here, a strong difference is related to the wider welfare and multilevel governance frame. The multilevel framework the cities are embedded in significantly impacts how the local welfare can counteract inequalities and vulnerabilities (Kazepov, 2010), forming specific nationallocal combinations that go beyond the inclusion within the established welfare states typologies. In the Danish and Viennese case, the national and local welfare, as well as education provision, is seen as the main tool to face the polarisation brought about by knowledge economy trends, thus providing a quite solid safety net to rely upon. However, the specific profile of the state-city relationship differs, when addressing the integration between competitiveness and social inclusion. Aarhus relies highly on the characteristics of the developed Danish welfare system, which provides comparatively wide coverage of protection to people in need, with priority on service provision and human capital development.

The overall approach found in growth strategies presents, therefore, several common traits with knowledge economy and social investment advocates: the underlying assumption is that economic growth would benefit the city overall and thus will also help more deprived areas. In Vienna, the peculiar role of the city as a federal state in combination with its status as Austrian capital and its social-democratic tradition allow for greater autonomy and capacity of urban policies-leading to a pronounced difference with other Austrian cities. The emphasis on education and training builds upon the importance of higher education in the highly international Viennese context, as opposed to the major role played by vocational training and traditional apprenticeships provided within the dual system in most of the other urban contexts in Austria. Moreover, the long-standing tradition in the provision of affordable housing also plays a role in how the city plans to tackle rampant inequal- 
ities. In the case of Milan, the weaker and highly fragmented Italian welfare system is not considered as fully reliable support and the local welfare, even if developed by Italian standards (ITP4), does not seem able to overcome such shortage in social protection. Here, the international role played by the city contributes to the main importance of competitiveness, while growth documents attribute to social policies a much less effective and far-reaching scope.

\section{Concluding Discussion}

This contribution highlights how the association between competitiveness and integration is shaped through specific state-city relationships, creating mixed profiles that cannot be simply reconducted to nationallevel welfare states typologies. We analysed three urban centres positioning themselves in the global knowledge economy, considering local growth strategies and how they combine goals of competitiveness, internationalisation and social inclusion. The three cities are all drivers of growth and centres of attraction in their respective regions and countries, as indicated by trends of population growth and prevailing in-commuting. They are hubs of knowledge production and deployment in a context of learning economy.

Given these common premises, internationalisation trajectories of the three cities in a globalised network of course differ. This is also related to the role of urban policies within the national welfare framework, in mediating economic trends towards globalisation and internationalisation. Since the three cities are embedded in different national welfare regimes (Esping-Andersen, 1990), the attribution of responsibilities in design and implementation of social policies varies among scalar levels, from the national to the local and urban, in the EU countries (Kazepov, 2010). This variation gives Vienna, Aarhus and Milan different room for actions to counteract exclusionary processes.

In the literature, the capacity of welfare states and cities to foster integration and promote competitiveness is frequently debated (Morel, Palier, \& Palme, 2012). According to Cucca and Ranci (2016), the dynamics of welfare retrenchment and rescaling recently brought about a loss of synchronisation among these two crucial dimensions. The result is the continuous growth of socioeconomic inequalities and socio-spatial segregation in European cities, but also the differentiation of urban trajectories in reacting or limiting such de-synchronisation. In this article, we targeted this nexus through the specific point of view given by urban growth documents on the level of rhetoric, agenda-setting and programming, rather than on policy outputs and outcomes. We looked at how these narratives integrate or show awareness of the two goals of competitiveness and social inclusion.

The association between growth and integration in European cities has long been considered the distinctive trait of European cities. However, the debate on glob- alisation and the knowledge economy, on welfare retrenchment and rescaling, observed the growth of polarisation and inequalities, with some scholars stating the crisis of the previously established European city model (Häußermann, 2005). This article provided novel comparative evidence on this issue, looking at it from the perspective of urban growth strategies. The results show awareness of the polarising consequences of the knowledge economy, as well as plans and tools to address these shortcomings. Nonetheless, if a complete disconnection between competitiveness and integration is not to be found, how it is addressed shows relevant ambiguities and differences. Rhetorically, the reliance on beneficial spill-over effects of economic growth risks the recalling of neoliberal arguments undermining the role of social policies in protecting disadvantaged groups and areas. The priority attributed to social interventions seems instead to be strongly connected to the state-city relationship, highlighting both the importance of the welfare framework and the specific urban policy tradition. In this regard, the emphasis put on education recalls the role attributed to the public enhancement of human capital within the social investment debate (Hemerijck, 2017). On the negative side, the highly differentiated pattern of state-city relationship, resulting from urban growth strategies but also policy and service provision, could even bring about an increase in spatial disparity across territories within countries.

As a limitation of the study, it should be noted that the analysis of urban growth strategy remains on the level of planning, agenda-setting of goals and priorities. Following contributions should also shed light on how policies are designed following or not following such strategies; on the process of implementation and the outcomes achieved. Moreover, our results call for further research on the crucial state-city nexus when addressing economic and social objectives, adding in-depth comparative evidence through specific case studies, as well as building on previous evidence in order to propose typologies of cities that account for national and local variations in addressing socio-economic challenges.

\section{Acknowledgments}

This project has received funding from the European Union's Horizon 2020 research and innovation programme, under grant agreement No. 727058.

\section{Conflict of Interests}

The authors declare no conflict of interests.

\section{References}

Aarhus Municipality. (n.d.). Aarhus in numbers. Aarhus Kommune. Retrieved from https://www.aarhus.dk/ om-kommunen/aarhus-i-tal/aarhus-i-tal

Aarhus Municipality. (2015). Smart growth towards 
2050-Planning strategy 2015. Aarhus: Aarhus Municipality.

Aarhus Municipality. (2017a). Municipal Plan 2017-The main structure. Aarhus: Aarhus Municipality.

Aarhus Municipality. (2017b). International strategy for growth in Aarhus. Aarhus: Aarhus Municipality.

Aarhus Municipality. (2017c). Business plan 2018-2019. Aarhus: Aarhus Municipality.

Arundel, A., Lorenz, E., Lundvall, B. Å., \& Valeyre, A. (2007). How Europe's economies learn: A comparison of work organization and innovation mode for the EU-15. Industrial and Corporate Change, 16(6), 1175-1210.

Autor, D. (2014). Skills, education and the rise of earnings inequality among the 'other 99 percent.' Science, 344(6186), 843-851.

Bagnasco, A., \& Le Galès, P. (2000). Introduction: European cities: Local societies and collective actors. Cities in Contemporary Europe. https://doi.org/ 10.1017/СВO9780511558733.002

Berman, E., Bound, J., \& Machin, S. (1998). Implications of skill-biased technological change: International evidence. The Quarterly Journal of Economics, 113(4), 1245-1279.

Brown, P., Lauder, H., \& Ashton, D. (2010). The global auction: The broken promises of education, jobs, and incomes. Oxford: Oxford University Press.

Camera di Commercio di Milano, Monza e Lodi. (2020). Milano produttiva [Productive Milan]. Milan: Camera di Commercio. Retrieved from https:// www.milomb.camcom.it/documents/10157/ 41966981/Miprod-2020.pdf/f56ad64e-5474-444da586-ff05d5623c73

Castells, M. (1996). The rise of the network society, the information age: Economy, society and culture, Vol. 1. Cambridge, MA: Blackwell.

Comune di Milano. (2014). Milano smart city. Linee guida [Smart city Milan. Guidelines]. Milan: Comune di Milano.

Comune di Milano. (2016). Linee programmatiche relative alle azioni ed ai progetti da realizzare nel corso del mandato [Programmatic lines related to projects and actions to be carried out during the mandate]. Milan: Comune di Milano.

Comune di Milano. (2017). Documento Unico di Programmazione 2017-2019 [Programmatic document 2017-2019]. Milan: Comune di Milano.

Comune di Milano. (2018). Bando alle periferie 2018 [Call for the peripheries 2018]. Milan: Comune di Milano.

Comune di Milano. (2019). Piano di governo del territorio [Plan of government of territory]. Milan: Comune di Milano.

Coppola, F., Daveri, F., Negri, V., \& Saini, S. (2018). Revamping growth in an advanced country: The case of Milano. Milan: Assolombarda. Retrieved from https://www.assolombarda.it/centro-studi/ the-case-of-milano-report-completo

Cucca, R., \& Ranci, C. (Eds.). (2016). Unequal cities: The challenge of post-industrial transition in times of austerity. London: Routledge.

D'Ovidio, M. (2016). The creative city does not exist. Critical essays on the creative and cultural economy of cities. Milan: Ledizioni.

de Neergaard, M., Arp Fallov, M., Skovgaard Nielsen, R., \& Jørgensen, A. (2020). Contexts and interconnections: A conjunctural approach to territorial cohesion. Social Inclusion, 8(4), 277-286.

Direzione Economia Urbana e Lavoro. (2017). Manifattura Milano. Linee guida [Milan manufacturing. Guidelines]. Milan: Comune di Milano.

Dijkstra, L. (2017). My region, my Europe, our future. Seventh report on economic, social and territorial cohesion. Luxembourg: Publications Office of the European Union.

DTI. (1998). Our competitive future-Building the knowledge driven economy: Analysis and background. London: HMSO.

Emmenegger, P., S., Häusermann, S., Palier, B., \& SeeleibKaiser, M. (Eds.). (2012). The age of dualization: The changing face of inequality in deindustrializing societies. New York, NY: Oxford University Press USA.

Esping-Andersen, G. (1990). The three worlds of welfare capitalism. Princeton, NJ: Princeton University Press.

Esping-Andersen, G. (1999). Social foundations of postindustrial economies. Oxford: Oxford University Press.

ESPON. (2017). Territorial cooperation for the future of Europe: Territorial review. Luxembourg: ESPON.

Eurostat. (n.d.). Datawarehouse. Eurostat. Retrieved from https://ec.europa.eu/eurostat/data/database

Florida, R. L. (2002). The rise of the creative class: And how it's transforming work, leisure, community and everyday life. New York, NY: Basic Books.

Flyvbjerg, B. (2006). Five misunderstandings about casestudy research. Qualitative Inquiry, 12(2), 219-245.

Glaser, E. L., Resseger, M., \& Tobio, K. (2008). Urban inequality (Working Paper No. 14419). Cambridge, MA: NBER.

Guest, G., MacQueen, K. M., \& Namey, E. E. (2012). Applied thematic analysis. Thousand Oaks, CA: SAGE.

Häußermann, H. (2005). The end of the European city? European Review, 13(2), 237-249.

Häußermann, H., \& Haila, A. (2005). The European city: A conceptual framework and normative project. In Y. Kazepov (Ed.), Cities of Europe: Changing contexts, local arrangements, and the challenge to urban cohesion (pp. 43-63). Malden, MA: Blackwell.

Hemerijck, A. (Ed.). (2017). The uses of social investment. Oxford: Oxford University Press.

lammarino, S., Rodriguez-Pose, A., \& Storper, M. (2018). Regional inequality in Europe. Evidence, theory and policy implications. Journal of Economic Geography, 53, 898-924.

ISTAT. (n.d.). ISTAT Statistiche [ISTAT statistics]. Istituto Nazionale di Statistica. Retrieved from http://dati. istat.it

Kazepov, Y. (Ed.). (2010). Rescaling social policies: To- 
wards multilevel governance in Europe. Farnham: Ashgate Publishing.

Kazepov, Y., Saruis, T., \& Colombo, F. (2020). The multiscalar puzzle of social innovation. In S. Oosterlynck, A. Novy, \& Y. Kazepov (Eds.), Local social innovation to combat poverty and exclusion. A critical appraisal (pp. 91-112). Bristol: Policy Press.

Kenway, J., Bullen, E., Fahey, J., \& Robb, S. (2006). Haunting the knowledge economy. London: Routledge.

Landesmann, M., \& Römisch, R. (2006). Economic growth, regional disparities and employment in the EU-27 (Research Rerport). Vienna: Vienna Institute for International Economic Studies.

Lundvall, B.-A. (2016). The learning economy and the economics of hope. London: Anthem Press.

Morel, N., Palier, B., \& Palme, J. (2012). Towards a social investment welfare state? Ideas, policies and challenges. Bristol: Policy Press.

Musterd, S., \& Murie, M. (Eds.). (2010). Making competitive cities. Oxford: Wiley-Blackwell.

OECD. (1996). The knowledge-based economy. Paris: OECD.

OECD. (2006). Competitive cities in the global economy. Paris: OECD.

OECD Statistics. (n.d.). Regional well-being: Regional income distribution and poverty. OECD. Retrieved from https://stats.oecd.org/index.aspx?queryid=58616

Powell, W., \& Snellman, K. (2004). The knowledge economy. Annual Review of Sociology, 30(1), 199-220.

Ranci, C., Brandsen, T., \& Sabatinelli, S. (Eds.). (2014). Social vulnerability in European cities: The role of local welfare in times of crisis. New York, NY: Springer.

Rodrigues, M. J. (2006). The European way to a knowledge-intensive economy-The Lisbon strategy. In M. Castells \& G. Cardoso (Eds.), The network society: From knowledge to policy (pp. 405-424). Washington, DC: Centre for Transatlantic Relations.
Rowthorn, R., \& Ramaswamy, R. (1997). Deindustrialization: Causes and Implications (IMF Working Paper No. 97/42). Washington, DC: International Monetary Fund.

Statistics Austria. (n.d.). Registerzählung 2011 [Register census 2011]. Statistics Austria. Retrieved from https://www.statistik.at/web_de/statistiken/ menschen_und_gesellschaft/bevoelkerung/ volkszaehlungen_registerzaehlungen_ abgestimmte_erwerbsstatistik/index.html

Statistics Denmark. (n.d.). Population and election. Statistics Denmark. Retrieved from https://www. statistikbanken.dk

Vicari, S. (2010). Brand-building the creative city: A critical look at current concepts and practices. Florence: Florence University Press.

Vienna Municipal Department 18. (2014a). Urban development plan Vienna 2025. Vienna: City of Vienna. Retrieved from http://media.obvsg.at/AC123783202001

Vienna Municipal Department 18. (2014b). Smart city Vienna: Framework strategy. Overview. Vienna: City of Vienna.

Vienna Municipal Department 18. (2017). STEP 2025 Fachkonzept-Produktive Stadt [STEP 2025 technical concept-Productive city]. Vienna: City of Vienna.

Vienna Municipal Department 23. (2015). Innovative Vienna 2020: Vienna's research, technology and innovation strategy. Vienna: City of Vienna.

Vienna Municipal Department 23. (2018). Qualifikationsplan Wien 2030 [Qualifications Plan Vienna 2030]. Vienna: City of Vienna.

Vienna Municipality Statistical Office. (n.d.). Statistics Vienna. Vienna Municipality. Retrieved from https://www.wien.gv.at/statistik/bevoelkerung/ bevoelkerungsstand

\section{About the Authors}

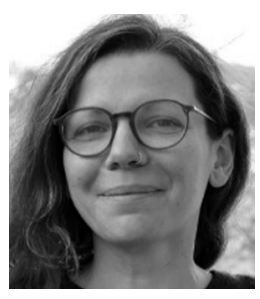

Tatjana Boczy is a Research Assistant at the Department of Sociology at the University of Vienna since 2018. Previously (2013-2014), she was an Undergraduate Research Assistant at the Department of Sociology of the University of Innsbruck. She completed a master's degree in Sociology at the University of Innsbruck in 2017. Her research interests include urban and regional research, social change and transformations, political sociology, sociological theory, mixed-methods research.

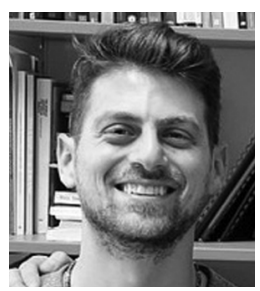

Ruggero Cefalo earned his PhD in 2017. He is a Postdoctoral Researcher at the University of Vienna, Department of Sociology, where he teaches political sociology and comparative welfare analysis and social policy in comparative perspective. He is particularly interested in educational and labour policies, school-to-work transitions and youth studies. He has participated in the Horizon 2020 Projects YOUNG ADULLLT and COHSMO. Among his recent publications is Youth Labor Market Integration in European Regions (with R. Scandurra and Y. Kazepov). 


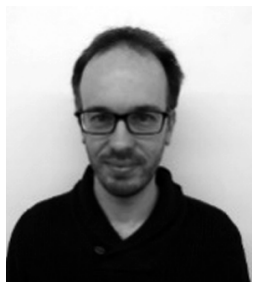

Andrea Parma is a Junior Researcher at the Department of Architecture and Urban Studies of Polytechnic of Milan. In 2012, he obtained his PhD in Applied sociology and social research methodology at the University of Milan-Bicocca. Since 2015, he has been collaborating with the Social Policy Laboratory of Polytechnic of Milan. In recent years, his research interests have focused on social cohesion, economic insecurity, the labour market and school segregation. Since 2017, he has been involved in the Horizon 2020 project COHSMO.

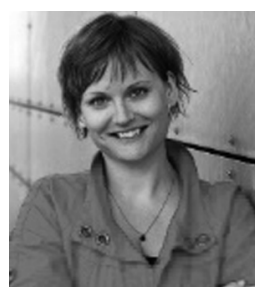

Rikke Skovgaard Nielsen is a Senior Researcher of Department of the Built Environment, Aalborg University, Denmark, and coordinates the Master Program "City, Housing and Settlement Patterns." Rikke's research is centred on inequality, deprived neighbourhoods, diversity, segregation and regeneration plans. Of major international research projects, she has taken part in the NORFACE project NODES, the EU FP7 project DIVERCITIES and currently the Horizon 2020 project COHSMO. Recent publications include Governance Arrangements Targeting Diversity in Europe: How New Public Management Impacts Working with Social Cohesion (https://doi.org/10.1080/02723638.2018.1511190). 